OPEN ACCESS

Edited by:

Aurelio Salerno,

Independent Researcher, Barcelona,

Spain

Reviewed by:

Vincenzo Quagliariello,

Istituto Nazionale Tumori Fondazione

G. Pascale (IRCCS), Italy

Javier Saurina,

University of Barcelona, Spain

*Correspondence:

Jayanth Panyam

jayanth.panyam@temple.edu

Specialty section:

This article was submitted to

Biomaterials,

a section of the journal

Frontiers in Bioengineering and

Biotechnology

Received: 08 December 2020

Accepted: 19 January 2021

Published: 18 February 2021

Citation:

Oseni BA, Azubuike CP.

Okubanjo OO, Igwilo $\mathrm{Cl}$ and

Panyam J (2021) Encapsulation

of Andrographolide

in poly(lactide-co-glycolide)

Nanoparticles: Formulation

Optimization and in vitro

Efficacy Studies.

Front. Bioeng. Biotechnol. 9:639409.

doi: 10.3389/fbioe.2021.639409

\section{Encapsulation of Andrographolide in poly(lactide-co-glycolide) Nanoparticles: Formulation Optimization and in vitro Efficacy Studies}

\author{
Bukola A. Oseni,2, Chukwuemeka P. Azubuike ${ }^{1}$, Omotunde O. Okubanjo', \\ Cecilia I. Igwilo ${ }^{1}$ and Jayanth Panyam ${ }^{2,3 *}$
}

\begin{abstract}
'Department of Pharmaceutics and Pharmaceutical Technology, University of Lagos, Lagos, Nigeria, ${ }^{2}$ Department of Pharmaceutics, University of Minnesota, Minneapolis, MN, United States, ${ }^{3}$ School of Pharmacy, Temple University, Philadelphia, PA, United States
\end{abstract}

Andrographolide is a potential chemopreventive and chemotherapeutic agent that suffers from poor aqueous solubility. Encapsulation in poly(lactide-co-glycolide) (PLGA) nanoparticles can overcome solubility issues and enable sustained release of the drug, resulting in improved therapeutic efficacy. In this study, andrographolide was encapsulated in PLGA nanoparticles via emulsion solvent evaporation technique. Effect of various formulation parameters including polymer composition, polymer molecular weight, polymer to drug ratio, surfactant concentration and the organic solvent used on nanoparticle properties were investigated. A selected formulation was used to determine the effect of encapsulation in nanoparticles on andrographolide's in vitro anticancer efficacy. Nanoparticles formulated using a polymer with 85:15 lactide to glycolide ratio and ethyl acetate as the organic solvent were found to be optimal based on average hydrodynamic particle size $(135 \pm 4 \mathrm{~nm})$ and drug loading $(2.6 \pm 0.6 \% \mathrm{w} / \mathrm{w})$. This formulation demonstrated sustained release of andrographolide over $48 \mathrm{~h}$ and demonstrated significantly greater in vitro anticancer efficacy compared to free drug in a metastatic breast cancer cell line. These results suggest that additional, more in-depth efficacy studies are warranted for the nanoparticle formulation of andrographolide.

Keywords: andrographolide, poly(lactide-co-glycolide), nanoparticles, formulation optimization, breast cancer

\section{INTRODUCTION}

According to GLOBOCAN-a cancer database created by the International Agency for Research on Cancer (IARC), there is an increase in the global incidence and deaths due to cancer. In 2012, approximately 14.1 million new cases and deaths were recorded (Ferlay et al., 2015) rising to about 18.1 million new incidence and 9.6 million deaths in 2018 (Bray et al., 2018; Ferlay et al., 2019). 
Breast cancer remains the most common cancer type globally as well as the cause of most deaths associated with cancer in women. In 2018, breast cancer accounted for $24.2 \%$ incidence and $15.0 \%$ cancer-related deaths in women (Bray et al., 2018; Ferlay et al., 2019).

Chemotherapy is a mainstay treatment modality employed in the management of cancer. Chemotherapeutic agents such as doxorubicin, cisplatin, and paclitaxel have been utilized in the treatment of breast cancer (Takimoto and Calvo, 2005); however, the major drawback includes the development of resistance and life-threatening side effects (due to non-specificity of the chemical agents to cancerous cells) such as cardiac toxicity, hair loss, bone marrow suppression, and gastrointestinal tract lesions, amongst others (Igarashi, 2008; Monsuez et al., 2010; Nussbaumer et al., 2011). An ideal chemotherapeutic agent will exhibit minimal or no side effects while having intrinsic ability to prevent the development of resistance. No such drug currently exists. Research into new therapeutic agents with the aim of overcoming the above limitations therefore continues to be highly relevant. Natural products of plant origin present a source of potential drug molecules (Hosseini and Ghorbani, 2015); many phytochemicals have been shown experimentally to possess cytotoxic activity against various cancer types (Hadjzadeh et al., 2006; Shu et al., 2010; Tan et al., 2011; Wilken et al., 2011; Lè Ne Teiten et al., 2013).

Andrographolide is a labdane diterpenoid derived from the Andrographis paniculata plant (Niranjan et al., 2010; Jayakumar et al., 2013). It is the major bioactive compound in the plant and has been found to possess antimicrobial, hepatoprotective, anticancer, anti-inflammatory, and immunostimulatory activities (Jarukamjorn and Nemoto, 2008; Levita et al., 2010; Lim et al., 2012). The cytotoxic activity of this molecule against various cancer types including ovarian, lung, hepatoma, breast, prostate, and colon cancer has been attributed to its ability to act on several cell signaling pathways. Andrographolide exerts direct chemotherapeutic activity via cell cycle arrest at the G0/G1 or G2/M phase. In addition, the drug has also been shown to induce increased production of interleukin 2 (IL2) and interferon gamma (IFN- $\gamma$ ), which activate cytotoxic $\mathrm{T}$ lymphocytes as well as TNF related apoptosis inducing ligand (TRAIL) and death receptors, which eventually leads to apoptosis (Ajaya Kumar et al., 2004; Sheeja and Kuttan, 2007; Mishra, 2016). In addition, the drug inhibits the generation of pro-inflammatory mediators such as tumor necrosis factor alpha (TNF alpha) and angiogenesis mediators such as vascular endothelial growth factor (VEGF) and nitric oxide (NO). In order to combat cancer resistance, it has been suggested that drug molecule(s) activating different death pathways should be utilized. Therefore, a drug molecule such as andrographolide having multiple mechanisms of anticancer activity will be a suitable candidate. Andrographolide, however, has low aqueous solubility, poor bioavailability, and short half-life, resulting in reduced therapeutic activity (Roy et al., 2012; Ghosh et al., 2016). These barriers can be mitigated by the use of a suitable delivery system. In our previous study, andrographolide was formulated into an emulsion, with the particle size in the micrometer range (Oseni et al., 2020). However, microparticles have relatively low cell uptake and poor tissue penetration. Particles in the nanometer size range (nanoparticles) are more advantageous because of their ability to passively accumulate in tumors via the "enhanced permeability and retention effect" (Bharathala and Sharma, 2019).

Nanoparticles are typically fabricated using natural or synthetic polymers such as chitosan, gelatin, albumin, poly(lactide-co-glycolide) (PLGA), polylactide (PLA), and hyaluronan, amongst others (Pal et al., 2011; Bhatia, 2016). They have been used as carriers for the delivery of small molecules, biologic macromolecules, diagnostic agents, and vaccines (Petros and DeSimone, 2010; Bahrami et al., 2017). Encapsulation in nanoparticles can overcome poor aqueous solubility issues because appropriately formulated nanoparticles exhibit excellent suspension stability in biologic fluids (Jacob et al., 2020). PLGA is an FDA-approved synthetic polymer widely used to formulate drug carriers because the polymer is biocompatible and biodegradable, and nanoparticles formulated using PLGA allow for sustained release of various types of payload and can be surface functionalized for targeted delivery applications (Kumari et al., 2010; Danhier et al., 2012; Gentile et al., 2014; Rizvi and Saleh, 2018).

In this study, the encapsulation of andrographolide in PLGA nanoparticles was explored, and the effect of various formulation parameters such as organic solvent, molecular weight of polymer, and lactide:glycolide ratio on key nanoparticle properties such as size, drug loading (DL), and drug release rate were characterized. The formulation of choice with desired physical properties, optimum DL, and in vitro release profile was subjected to in vitro cytotoxicity studies using LM2 breast cancer cells (a metastatic variant of the MDA-MB-231 triple negative breast cancer parent cells). Our study shows that the optimized nanoparticulate formulation of andrographolide demonstrates greater and more sustained cytotoxic effect vis à vis the free drug.

\section{MATERIALS AND METHODS}

\section{Materials}

Poly(lactide-co-glycolide) polymer of various lactide:glycolide ratios $(50: 50,65: 35,75: 25,85: 15,100: 0)$ as well as of different molecular weights $(0.26-0.54,0.55-0.75,0.76-0.94$, and $0.95-$ $1.20 \mathrm{dL} / \mathrm{g}$ inherent viscosity; all of them were 50:50 lactide to glycolide ratio) was purchased from LACTEL (Birmingham AL). Polyvinyl alcohol (87-90\% hydrolyzed, MW 30,00070,000 Da; PVA), flow buffer, RNase, propidium iodide, dimethylsulfoxide (DMSO), phenazine methosulfate (PMS), and andrographolide were purchased from Sigma Aldrich (St. Louis, MO, United States); tween 20 and all organic solvents (HPLC grade) were purchased from Fischer Scientific (Rockford, IL, United States); phosphate buffered saline (PBS), minimum essential medium (MEM), fetal bovine serum (FBS), penicillin, and streptomycin were procured from Gibco; MTS [3-(4,5-dimethylthiazol-2-yl)-5-(3-carboxymethoxyphenyl)-2(4-sulfophenyl)-2H-tetrazolium] reagent was obtained from Promega; and $0.5 \% \mathrm{w} / \mathrm{v}$ uranyl acetate was procured from VWR (Radnor PA). 


\section{Cell Line}

The LM2 breast cancer cell line was cultured in MEM supplemented with $10 \% \mathrm{FBS}, 100 \mathrm{UI} / \mathrm{mL}$ of penicillin, and $100 \mu \mathrm{g} / \mathrm{mL}$ streptomycin (referred to as complete media).

\section{Methods}

\section{Preparation of Andrographolide Nanoparticles}

The andrographolide-loaded PLGA nanoparticles were prepared using the emulsion solvent evaporation method (Toti et al., 2011; Kim et al., 2018a). Briefly, PVA was dispersed in DI water to obtain the aqueous phase; andrographolide and PLGA were dissolved in $1 \mathrm{~mL}$ of chloroform and $200 \mu \mathrm{L}$ methanol. The organic phase was added into $8 \mathrm{~mL}$ of the PVA solution. The mixture was sonicated at 18-20 W for 5 min over ice bath using a probe sonicator (Sonicator XL, Misonix, Melville, NY). The resulting emulsion was placed on the magnetic stirrer (Super-Nuova, Swedesboro, NJ) for $17 \mathrm{~h}$ to remove the organic solvent. The nanoparticle suspension formed was then placed under vacuum for $1 \mathrm{~h}$ to remove residual organic solvent. The nanoparticles were recovered via centrifugation (Optima XPN-80 Ultracentrifuge, Beckman Coulter Inc., Fullerton, CA) at 35,000 rpm for $35 \mathrm{~min}$ and washed three times with DI water and recovered by ultracentrifugation between each washing step. After the final wash step, nanoparticles were resuspended in DI water, lyophilized (Labconco FreeZone 4.5, Kansas City, MO), and stored at $-20^{\circ} \mathrm{C}$ till further analysis.

The effect of formulation variables (lactide:glycolide ratio, inherent viscosity of polymer, organic solvent, surfactant concentration, and drug to polymer ratio) was evaluated for optimization of the formulation (Table 1). Some minor modifications were made in the formulation fabricated using ethyl acetate as the organic solvent because of the lower solubility of the polymer in the solvent. Briefly, andrographolide and PLGA were dissolved in $1.7 \mathrm{~mL}$ of ethyl acetate and $330 \mu \mathrm{L}$ of methanol. The organic phase was added to $8 \mathrm{~mL}$ of the aqueous phase. The mixture was sonicated at $18-20 \mathrm{~W}$ for $5 \mathrm{~min}$ using a probe sonicator, and the emulsion was placed on a magnetic stirrer for $17 \mathrm{~h}$ in ambient conditions and further under vacuum for $1 \mathrm{~h}$. Nanoparticles were recovered via centrifugation at 45,000 rpm for $1 \mathrm{~h}$ and washed three times with DI water. The nanoparticles

TABLE 1 | Constituents of the formulation showing the parameters investigated to obtain the optimized formulation.

\begin{tabular}{|c|c|c|c|c|c|}
\hline Formulation code & $\begin{array}{l}\text { Lactide to glycolide } \\
\text { ratio }\end{array}$ & Inherent viscosity (dL/g) & Organic solvent & Drug to polymer ratio & $\begin{array}{l}\text { PVA surfactant } \\
\text { concentration }\end{array}$ \\
\hline \multicolumn{6}{|l|}{ Lactide:glycolide } \\
\hline A2 & $65: 35$ & 0.75 & Chloroform & $1: 6$ & 2.5 \\
\hline A3 & $75: 25$ & $0.55-0.75$ & Chloroform & $1: 6$ & 2.5 \\
\hline A4 & $85: 15$ & 0.64 & Chloroform & $1: 6$ & 2.5 \\
\hline \multicolumn{6}{|l|}{ Organic solvent } \\
\hline $\mathrm{B} 1^{\mathrm{a}}$ & $50: 50$ & $0.55-0.75$ & Chloroform & $1: 6$ & 2.5 \\
\hline B2 & $50: 50$ & $0.55-0.75$ & Dichloromethane & $1: 6$ & 2.5 \\
\hline $\mathrm{B}^{\mathrm{b}}$ & $50: 50$ & $0.55-0.75$ & Ethyl acetate & $1: 6$ & 2.5 \\
\hline B4 & $50: 50$ & $0.55-0.75$ & Acetone & $1: 6$ & 2.5 \\
\hline \multicolumn{6}{|l|}{ Inherent viscosity } \\
\hline $\mathrm{C} 4$ & $50: 50$ & $0.95-1.20$ & Ethyl acetate & $1: 6$ & 2.5 \\
\hline \multicolumn{6}{|l|}{ Drug:Polymer } \\
\hline D1 & $50: 50$ & $0.55-0.75$ & Ethyl acetate & $1: 20$ & 2.5 \\
\hline D2 & $50: 50$ & $0.55-0.75$ & Ethyl acetate & $1: 12$ & 2.5 \\
\hline $\mathrm{D}^{\mathrm{C}}$ & $50: 50$ & $0.55-0.75$ & Ethyl acetate & $1: 8.5$ & 2.5 \\
\hline $\mathrm{D} 4^{\mathrm{b}}$ & $50: 50$ & $0.55-0.75$ & Ethyl acetate & $1: 6$ & 2.5 \\
\hline D5 & $50: 50$ & $0.55-0.75$ & Ethyl acetate & $1: 4$ & 2.5 \\
\hline \multicolumn{6}{|c|}{ Surfactant concentration } \\
\hline E1 & $50: 50$ & $0.55-0.75$ & Ethyl acetate & $1: 8.5$ & 1 \\
\hline E2 & $50: 50$ & $0.55-0.75$ & Ethyl acetate & $1: 8.5$ & 2 \\
\hline$E 3^{c}$ & $50: 50$ & $0.55-0.75$ & Ethyl acetate & $1: 8.5$ & 2.5 \\
\hline
\end{tabular}

$a, b$, and $c$, same formulation variables; $F^{*}$, optimized formulation. 
were resuspended in DI water, lyophilized, and stored at $-20^{\circ} \mathrm{C}$ for further analysis.

\section{Characterization of Andrographolide PLGA Nanoparticles}

\section{Particle size, polydispersity index, and zeta potential}

The hydrodynamic diameter and polydispersity index (PI) of nanoparticles were determined via dynamic light scattering (DLS) technique (Delsa ${ }^{\mathrm{TM}}$ Nano C, Beckman Coulter, Inc.) (Kim et al., 2018a,b). The zeta potential was determined by measuring the electrophoretic mobility of the particles using Delsa ${ }^{\mathrm{TM}}$ Nano C. Nanoparticle suspension in DI water was sonicated for $30 \mathrm{~s}$ prior to analyses.

\section{Surface morphology}

Morphology of nanoparticles was determined using transmission electron microscopy (TEM) (FEI Tecnai G2 F30) (Grabowski et al., 2015). Nanoparticle suspension $(1 \mathrm{mg} / \mathrm{mL})$ in DI water was deposited on a copper grid. A $0.5 \% \mathrm{w} / \mathrm{v}$ uranyl acetate solution was added as negative stain, excess suspension was blotted out using a filter paper, and the grid was air dried and thereafter observed under the electron microscope.

\section{Drug loading and encapsulation efficiency}

Standard concentrations of $5-30 \mu \mathrm{g} / \mathrm{mL}$ in methanol of andrographolide reference standard were prepared and placed in a quartz cuvette; the absorbance of the various andrographolide solution prepared was obtained using an ultraviolet (UV) spectrophotometer (Beckman Coulter, Inc.) at $224 \mathrm{~nm}$ wavelength. A graph of absorbance against concentration of andrographolide was plotted. The UV method was validated in line with the International Conference on Harmonization guideline (International Conference on Harmonization, 2005).

Andrographolide was extracted from nanoparticles using methanol $(1 \mathrm{mg} / \mathrm{mL}, 1 \mathrm{~mL})$; the methanol was added to the nanoparticles and placed on a rotating shaker for $18 \mathrm{~h}$ (Toti et al., 2011). The dispersion was centrifuged at $13,000 \mathrm{rpm}$ for $20 \mathrm{~min}$, dilution of the supernatant was carried out, and the absorbance of the resulting solution was obtained at $224 \mathrm{~nm}$ wavelength. The procedure was repeated for nanoparticles devoid of the drug, and its absorbance was subtracted from the absorbance of nanoparticles with drug. This normalized absorbance value was used in calculating the amount of drug in nanoparticles. Drug loading (DL) and encapsulation efficiency (EE) were calculated using equations 1 and 2, respectively.

$$
\text { DL }(\% \mathrm{w} / \mathrm{w})=\text { weight of andrographolide }(\mathrm{mg}) \text { encapsulated }
$$$$
\text { in } 1 \mathrm{mg} \text { of nanoparticle } \times 100
$$

$$
\mathrm{EE}(\%) \frac{\text { Experimental amount of drug per mg nanoparticle }}{\text { Theoretical amount of drug per mg nanoparticle }} \times 100
$$

\section{In vitro Release Study}

Drug release from nanoparticles was determined in (PBS, pH 7.4) with $0.2 \%$ tween 20 release buffer using a previously reported method (Toti et al., 2011). Nanoparticle suspensions $(0.5 \mathrm{mg} / \mathrm{mL}$, $2 \mathrm{~mL}$ ) in release buffer were transferred into several tubes; the tubes were placed in a water bath shaker at $100 \mathrm{rpm}, 37^{\circ} \mathrm{C}$. At predetermined intervals $(1,2,6,24,48$, and $72 \mathrm{~h})$, three tubes were centrifuged at $13,000 \mathrm{rpm}$ for $10 \mathrm{~min}$. The supernatant was analyzed for drug content via UV spectroscopy at $224 \mathrm{~nm}$.

\section{In vitro Anticancer Efficacy Studies \\ In vitro acute viability}

LM2 breast cancer cells were cultured in complete MEM in an incubator at $37^{\circ} \mathrm{C}$ and $5 \% \mathrm{CO}_{2}$ until they were $80 \%$ confluent. The cells were seeded in a 96-well plate $\left(1 \times 10^{4}\right.$ cells in $100 \mu \mathrm{L}$ MEM) and allowed to attach overnight. Cells were incubated with various concentrations of andrographolide solution in DMSO or equivalent concentration of nanoparticles $(6.25-50 \mu \mathrm{M})$ for $48 \mathrm{~h}$. Medium only and medium containing $50 \mu \mathrm{M}$ of DMSO or PLGA blank nanoparticles were used as controls. At the end of the incubation period, treatments were removed, cells were washed with PBS, and $100 \mu \mathrm{L}$ of MTS reagent (containing MTS:PMS:MEM) was added and placed in the incubator at $37^{\circ} \mathrm{C}$, $5 \% \mathrm{CO}_{2}$ for $1.5 \mathrm{~h}$. Absorbance was determined at $490 \mathrm{~nm}$ using a microplate reader (BioTek Instruments, Inc., VT, United States). Percentage cell viability was calculated as a percentage of number of viable cells in each treatment group relative to that in the untreated control, and $\mathrm{IC}_{50}$ (concentration required to cause $50 \%$ reduction in the number of viable cells) was determined (Yallapu et al., 2010).

To determine the potential effects of DMSO and blank PLGA nanoparticles, the MTS assay was repeated with $20 \mu \mathrm{M}$ of free drug, drug-loaded nanoformulation (equivalent concentration as free drug treatment), DMSO (equivalent to concentration present in the free drug), blank PLGA nanoparticles (same concentration of particles present in the nanoformulation), and medium (untreated cells). Percent cell viability was obtained for each treatment group to determine the cytotoxic effect of the DMSO solvent and blank nanoparticles on LM2 cells.

\section{In vitro sustained efficacy study}

The antiproliferative activity of the formulation and free drug was studied as described by Panyam et al. (Panyam and Labhasetwar, 2004). Briefly, LM2 cells were seeded in a 96-well plate $\left(1 \times 10^{4}\right.$ cells) and allowed to attach overnight. Cell viability via MTS Assay was carried out as described in section "In vitro Acute Viability"- this represents Day 0 with no drug treatment. Cells were treated with andrographolide nanoformulation or free drug at $20 \mu \mathrm{M}$ concentration and medium (control) for $48 \mathrm{~h}$, treatments were removed and replaced with fresh medium. The medium was changed every other day thereafter, and cell viability as a function of time (representing cell proliferation) was determined via MTS Assay.

\section{Cell cycle analysis}

The percent cell number in different phases of cell cycle was determined using flow cytometry as described by Rajagopal et al. (2003), with slight modifications. Briefly, LM2 cells were seeded in a 6-well plate $\left(3 \times 10^{5}\right.$ cells in $3 \mathrm{~mL}$ complete MEM) and allowed to attach overnight. The media was removed and replaced with FBS free MEM for $24 \mathrm{~h}$ to 
synchronize the cells to the same phase of the cell cycle. The cells were then incubated with free drug, andrographolide nanoformulation (equivalent to $20 \mu \mathrm{M}$ andrographolide), or complete medium (untreated control) for $48 \mathrm{~h}$. Cells were harvested by trypsinization and recovered via centrifugation at 1,000 rpm for $5 \mathrm{~min}$. Cells were washed with PBS, resuspended in ice cold $70 \%$ ethanol, and incubated at $4^{\circ} \mathrm{C}$ for $30 \mathrm{~min}$ to permeabilize the cells. Cells were washed twice with flow buffer and treated with RNase $(10 \mathrm{mg} / \mathrm{mL})$ at $37^{\circ} \mathrm{C}$ for $15 \mathrm{~min}$. The cells were then stained with propidium iodide $(0.5 \mathrm{mg} / \mathrm{mL})$ at room temperature for $2 \mathrm{~min}$; cells were washed and resuspended in flow buffer. DNA content was measured using BD LSR II H4760 flow cytometer (BD Biosciences, San Jose, CA, United States), and data were analyzed using the FlowJo software.

\section{Statistical Analysis}

Results were reported as mean \pm standard deviation (SD) or mean \pm standard error of mean (SEM). Statistical differences between groups were determined using one-way analysis of variance (ANOVA) followed by Tukey's post hoc test (if applicable) using the Graphpad ${ }^{\circledR} 5$ Prism software (GraphPad Software, La Jolla, CA, United States). A $p$-value $<0.05$ was considered significant.

\section{RESULTS AND DISCUSSION}

Andrographolide is a potential therapeutic agent shown to possess several beneficial pharmacological properties such as suppression of proinflammatory molecules- $\mathrm{TNF} \alpha$, inducible nitric oxide synthase (iNOS), and cyclo oxygenase 2 (COX 2); enhanced induction of immune modulator-IL-2 and induction of cell cycle arrest; and apoptosis, thereby eliciting antiinflammatory, immunomodulatory, and anticancer activities (Pandey and Rao, 2018). The multiple anticancer mechanisms exerted by andrographolide might be useful in preventing resistance associated with conventional chemotherapeutic agents. However, its low aqueous, poor bioavailability, and short half-life results in decreased activity, hence limiting its clinical translation. To overcome these issues, andrographolide nanoformulation was developed using PLGA polymer.

\section{Andrographolide Nanoparticle Preparation and Characterization}

The particle size of a formulation determines its in vivo disposition, extent of uptake by cells, and consequently its therapeutic efficacy. It is generally accepted that for in vivo applications, smaller particle size is preferred. Particles in the 1-3 nm are prone to clearance by renal filtration, while large particles are rapidly cleared by the reticuloendothelial system, thereby reducing their circulation time (Yin Win and Feng, 2005; Sadat et al., 2016). Furthermore, particles greater than $200 \mathrm{~nm}$ when administered intravascularly may cause embolization (Hickey et al., 2015). Nanoparticles in the 50-200 nm size have demonstrated the highest percentage of cellular uptake (Yin Win and Feng, 2005). However, nanoparticles that are less than $50 \mathrm{~nm}$ suffer from poor payload capacity (Jain and Thareja, 2019). Therefore, our desired particle size was 50 to $200 \mathrm{~nm}$.

Polydispersity Index is a measure of size distribution within a given sample (Danaei et al., 2018); it ranges from 0.0 (a perfect homogenously dispersed size population) to 1.0 (a heterogeneously dispersed system with multiple size populations). Formulations with wide range of particle distribution result in variations in DL, which will in turn lead to variability in drug release, bioavailability, and eventually efficacy (Betala et al., 2018). Formulations with $\mathrm{PI} \leq 0.20$ are generally acceptable for a polymer-based nanoformulation (Clarke, 2013; Danaei et al., 2018).

Zeta potential predicts the stability of a nano dispersion; higher absolute values (that is, either positive or negative) of zeta potential result in better suspension stability due to the presence of strong repulsive forces that prevent aggregation of particles (Sawant and Dodiya, 2008; Kedar et al., 2010). However, high surface charge on particles has been shown to result in increased macrophage uptake, resulting in increased clearance, reduced bioavailability and therapeutic efficacy (Honary and Zahir, 2013; Sadat et al., 2016). A formulation with decreased absolute value of surface charge and near zero value may have higher circulation time and higher accumulation in the tumor. For example, a previous study suggested that a formulation with particle size of about $150 \mathrm{~nm}$ and a slightly negative surface charge tend to accumulate more within tumor (Honary and Zahir, 2013; Sadat et al., 2016).

High DL and EE enables a reduction in the total amount of the formulation (and by extension, the formulation excipients) that needs to be administered for a given dose of the drug, thus preventing excipient-associated toxicity.

In the current study, we investigated the effect of various formulation parameters with the objective of optimizing the key nanoparticle properties discussed above.

\section{Effect of PLGA Lactide:Glycolide Ratio}

The effect of varying the lactide to glycolide ratio on various nanoparticle properties is shown in Table 2. In general, no correlation was observed between lactide to glycolide ratio and any of the physical properties. The average particle size varied from 194 to $209 \mathrm{~nm}$, while the PI varied from 0.08 to 0.20 and the zeta potential from -13.5 to $-23.5 \mathrm{mV}$. The DL of the formulations was in the $1.0-1.5 \% \mathrm{w} / \mathrm{w}$ range, with $\mathrm{EE}$ of $7.5-11.5 \%$. The 50:50 PLGA was chosen for further studies because that polymer consistently resulted in high DL compared to other polymers.

\section{Effect of Organic Solvents}

The effect of organic solvent used on nanoparticle properties is described in Table 3. Andrographolide nanoparticles made with 50:50 PLGA polymer and different organic solvents produced formulations having mean particle size in the range of 112 to $240 \mathrm{~nm}, \mathrm{PI}$ in the range of 0.10 to 0.20 , zeta potential of -10.6 to $-23.5 \mathrm{mV}$, DL of 1.5 to $2.3 \% \mathrm{w} / \mathrm{w}$, and $\mathrm{EE}$ of 11.5 to $18.2 \%$.

The chloroform (B1) and acetone (B4) formulations had similar particle size while the dichloromethane (B2) and ethyl acetate (B3) formulations had the largest and smallest particle 
TABLE 2 | Physicochemical properties and drug loading of andrographolide formulation with different lactide to glycolide ratio.

\begin{tabular}{|c|c|c|c|c|c|}
\hline Formulation code & Particle size (nm) & Polydispersity index (PI) & Zeta potential (mV) & Drug loading (\%) & Encapsulation efficiency (\%) \\
\hline $\mathrm{A} 1$ & $209 \pm 3$ & $0.20 \pm 0.01$ & $-23.5 \pm 3.8$ & $1.5 \pm 0.4$ & $11.5 \pm 2.9$ \\
\hline $\mathrm{A} 2$ & $197 \pm 7$ & $0.14 \pm 0.03^{\star}$ & $-14.4 \pm 0.1^{\star}$ & $1.0 \pm 0.2$ & $7.5 \pm 1.5$ \\
\hline A3 & $200 \pm 3$ & $0.09 \pm 0.01^{\star \star \star}$ & $-13.5 \pm 2.5^{\star}$ & $1.1 \pm 0.3$ & $9.1 \pm 2.8$ \\
\hline A4 & $194 \pm 2^{*}$ & $0.10 \pm 0.01^{\star \star \star}$ & $-17.2 \pm 5.6$ & $1.3 \pm 0.2$ & $9.8 \pm 1.7$ \\
\hline A5 & $202 \pm 6$ & $0.08 \pm 0.02^{\star \star \star}$ & $-16.2 \pm 1.8$ & $1.2 \pm 0.1$ & $8.7 \pm 1.0$ \\
\hline
\end{tabular}

Results are expressed as mean $\pm S D(n=3)$.

${ }^{*}$ signifies $p<0.05,{ }^{* * *}$ signifies $p<0.001$ significant differences with respect to A1. A1, 50:50 PLGA; A2, 65:35 PLGA; A3, 75:25 PLGA; A4, 85:15 PLGA; A5, 100 PLA.

TABLE 3 | Physicochemical properties and drug loading of andrographolide nanoformulation with different solvent.

\begin{tabular}{|c|c|c|c|c|c|}
\hline Formulation code & Particle size (nm) & Polydispersity index (PI) & Zeta potential (mV) & Drug loading (\%) & Encapsulation efficiency (\%) \\
\hline B1 & $209 \pm 3$ & $0.20 \pm 0.01$ & $-23.5 \pm 3.8$ & $1.5 \pm 0.4$ & $11.5 \pm 2.9$ \\
\hline B2 & $240 \pm 7^{\star \star \star}$ & $0.13 \pm 0.07$ & $-17.3 \pm 3.5$ & $1.7 \pm 0.3$ & $12.8 \pm 2.0$ \\
\hline B3 & $112 \pm 6^{\star \star \star}$ & $0.20 \pm 0.02$ & $-11.4 \pm 0.9^{*}$ & $2.3 \pm 0.3$ & $18.2 \pm 2.1$ \\
\hline B4 & $219 \pm 8$ & $0.10 \pm 0.01^{*}$ & $-10.6 \pm 4.7^{*}$ & $2.3 \pm 0.8$ & $17.8 \pm 6.2$ \\
\hline
\end{tabular}

Results are expressed as mean $\pm S D(n=3)$.

*signifies $p<0.05,{ }^{* * *}$ signifies $p<0.001$ significant differences with respect to B1 formulation. B1, chloroform; B2, dichloromethane; B3, ethyl acetate; B4, acetone.

size, respectively. A similar observation of reduced particle size with ethyl acetate organic solvent was demonstrated by Vineeth et al. (Vineeth et al., 2014); this is attributed to the low interfacial tension of ethyl acetate, which allows for the formation of a stable primary emulsion and consequently formation of smaller nanoparticles (Vineeth et al., 2014). All of these formulations except the one that utilized acetone had similar heterogeneity in size distribution; the acetone formulation had a lesser variation in size uniformity than the other three formulations. The chloroform and dichloromethane formulations (having similar values) had higher absolute charge but lower DL and EE than the ethyl acetate and acetone formulations (possessing similar charge, DL, and EE). The differences in the DL for the various formulations could have resulted in the differences in their zeta potential. The higher DL and EE observed in ethyl acetate and acetone formulations could be attributed to the properties of the solvents. Ethyl acetate and acetone have higher aqueous solubility than chloroform and dichloromethane; this could keep the drug soluble in the emulsion during the encapsulation process, allowing more of the drug to be entrapped in the polymer (Pauli et al., 2019). The ethyl acetate and acetone formulations therefore represent the preferred formulations with respect to surface charge, DL, and EE. The ethyl acetate formulation was chosen for further evaluation because of the lower particle size, higher DL, and EE.

\section{Effect of PLGA Molecular Weight}

Andrographolide nanoformulations prepared using ethyl acetate organic solvent and 50:50 PLGA polymer of different molecular weights (as measured through polymer inherent viscosities) had a mean particle size in the range of $107-143 \mathrm{~nm}$, PI of $0.10-0.20$, zeta potential of -8.1 to $-11.4 \mathrm{mV}$, DL of $1.1-2.3 \% \mathrm{w} / \mathrm{w}$, and $\mathrm{EE}$ of $8.4-18.2 \%$ as shown in Table 4.

The 6.7-31.3 kDa (C1) and 31.3-57.6 kDa (C2) formulations had similar smaller size than those of 57.6-91.6 $\mathrm{kDa}(\mathrm{C} 3)$ and
91.6-111.5 $\mathrm{kDa}(\mathrm{C} 4)$ formulations. This suggests that higher molecular weight of the polymer results in larger particle size. The increase in size associated with increased molecular weight can be attributed to the formation of a more viscous solution, which provides resistance to particle size breakdown, and thus more energy is required to achieve smaller particle size. All the formulations had similar size distribution and charge except for the 57.6-91.6 $\mathrm{kDa}$ formulation, which demonstrated lesser size variation and lower absolute surface charge value. However, this formulation had the lowest DL. The highest DL and EE was observed in the $31.3-57.6 \mathrm{kDa}$ polymer formulation. This polymer was chosen for further studies because of its small particle size, comparable size heterogeneity, and surface charge to the other formulations, highest DL, and EE.

\section{Effect of Drug-Polymer Ratio}

Andrographolide formulations with ethyl acetate organic solvent, 50:50 PLGA polymer (molecular weight $31.3-57.6 \mathrm{kDa}$ ) and having different drug-polymer ratios had a mean particle size in the range of 112 to $148 \mathrm{~nm}$, PI of 0.18 to 0.21 , zeta potential of -8.1 to $-11.4 \mathrm{mV}$, DL of $<1.0$ to $2.3 \% \mathrm{w} / \mathrm{w}$, and $\mathrm{EE}$ of $<9.8$ to 23.2\% as shown in Table 5.

The 1:20 (D1) and 1:12 (D2) drug-polymer ratio formulations were characterized by larger particle size than the 1:8.5 (D3) and 1:4 (D5) formulations, while the 1:6 (D4) formulation had the least particle size. All the formulations comprised particles with similar size distribution and surface charge. The DL of the 1:20 formulation could not be determined because the drug-polymer ratio was so low that the amount of drug encapsulated could not be detected or quantified accurately. Increase in drug-polymer ratio led to an increase in the amount of drug encapsulated until the 1:6 drug-polymer ratio; a further increase did not yield an increase in DL as observed in the 1:4 formulation. An initial increase in EE was observed with higher drug-polymer ratio, however, a further increase to 1:6 drug-polymer ratio led to a 
TABLE 4 | Physicochemical properties and drug loading of andrographolide formulation of different PLGA molecular weights.

\begin{tabular}{lccccc}
\hline Formulation code & Particle size $(\mathbf{n m})$ & Polydispersity index-PI & Zeta potential (mV) & Drug loading (\%) & Encapsulation efficiency (\%) \\
\hline C1 & $107 \pm 3$ & $0.20 \pm 0.03$ & $-10.4 \pm 0.9$ & $1.2 \pm 0.1^{\star \star \star}$ & $9.0 \pm 0.6^{\star \star \star}$ \\
C2 & $112 \pm 6$ & $0.20 \pm 0.02$ & $-11.4 \pm 0.9$ & $2.3 \pm 0.3$ & $18.2 \pm 2.1$ \\
C3 & $139 \pm 4^{\star \star *}$ & $0.10 \pm 0.05^{\star}$ & $-8.1 \pm 0.8^{\star}$ & $1.1 \pm 0.2^{\star \star \star}$ & $8.4 \pm 1.4^{\star \star \star}$ \\
C4 & $143 \pm 6^{\star \star \star}$ & $0.12 \pm 0.04$ & $-10.3 \pm 0.1$ & $1.5 \pm 0.1^{* \star}$ & $11.6 \pm 0.9^{* \star}$ \\
\hline
\end{tabular}

Results are expressed as mean $\pm S D(n=3)$.

${ }^{*}$ signifies $p<0.05,{ }^{* *}$ signifies $p<0.01,{ }^{* * *}$ signifies $p<0.001$ significant differences with respect to C2 formulation. C1, 6.7-31.3 kDa; C2, 31.3-57.6 kDa; C3, 57.6-91.6 kDa; C4, 91.6-111.5 kDa.

TABLE 5 | Physicochemical properties and drug loading of andrographolide nanoformulation with different drug-polymer ratio.

\begin{tabular}{lccccc}
\hline Formulation code & Particle size $(\mathbf{n m})$ & Polydispersity index-PI & Zeta potential $(\mathbf{m V})$ & Drug loading (\%) & Encapsulation efficiency (\%) \\
\hline D1 & $144 \pm 4^{\star \star \star}$ & $0.18 \pm 0.03$ & $-11.3 \pm 1.2$ & Unquantifiable & Unquantifiable \\
D2 & $148 \pm 5^{\star \star \star}$ & $0.20 \pm 0.02$ & $-8.2 \pm 1.2$ & $1.0 \pm 0.0^{\star \star \star}$ & $13.9 \pm 0.4$ \\
D3 & $133 \pm 2^{\star \star}$ & $0.20 \pm 0.03$ & $-10.1 \pm 2.0$ & $2.2 \pm 0.3$ & $23.2 \pm 3.7$ \\
D4 & $112 \pm 6$ & $0.20 \pm 0.02$ & $-11.4 \pm 10$ & $2.3 \pm 0.3$ & $18.2 \pm 2.1$ \\
D5 & $130 \pm 9^{\star}$ & $0.21 \pm 0.04$ & $-8.1 \pm 2.3$ & $1.8 \pm 0.3$ & $9.8 \pm 1.8^{\star \star}$ \\
\hline
\end{tabular}

Results are expressed as mean $\pm S D(n=3)$.

*signifies $p<0.05$, **signifies $p<0.01$, ${ }^{* *}$ signifies $p<0.001$ significant differences with respect to D4 formulation. D1, 1:20; D2, 1:12; D3, 1:8.5; D4, 1:6; D5, 1:4.

TABLE 6 | Physicochemical properties and drug loading of andrographolide nanoformulation with different PVA concentration.

\begin{tabular}{lccccc}
\hline Formulation code & Particle size $(\mathbf{n m})$ & Polydispersity index-PI & Zeta potential $(\mathbf{m V})$ & Drug loading (\%) & Encapsulation efficiency (\%) \\
\hline E1 & $163 \pm 1^{\star \star \star}$ & $0.17 \pm 0.02$ & $-14.1 \pm 1.1$ & $2.5 \pm 0.2$ & $24.3 \pm 1.7$ \\
E2 & $114 \pm 4^{\star \star \star}$ & $0.17 \pm 0.04$ & $-11.6 \pm 1.3$ & $2.8 \pm 0.4^{*}$ & $27.3 \pm 3.6$ \\
E3 & $133 \pm 2$ & $0.20 \pm 0.03$ & $-10.1 \pm 2.0$ & $2.2 \pm 0.3$ & $23.2 \pm 3.7$ \\
E4 & $137 \pm 1$ & $0.20 \pm 0.03$ & $-12.6 \pm 0.3$ & $1.2 \pm 0.1^{\star \star}$ & $12.6 \pm 0.5^{\star \star}$ \\
E5 & $129 \pm 1$ & $0.16 \pm 0.07$ & $-13.5 \pm 3.5$ & $1.3 \pm 0.1^{\star \star}$
\end{tabular}

Results are expressed as mean $\pm S . D(n=3)$. "signifies $p<0.05$, ${ }^{* *}$ signifies $p<0.01$, ${ }^{* *}$ signifies $p<0.001$ significant differences with respect to E3 formulation. E1, PVA $1 \%$ W/V, E2, PVA 2\% W/V, E3, PVA 2.5\% W/V, E4, PVA 3\% W/V, E5, PVA 4\% W/V.

decrease in the EE even though the amount of drug encapsulated is comparable to that of 1:8.5 formulation. This implies that an increase in the quantity of drug utilized in the formulation beyond the 1:8.5 ratio will be a waste of the drug material given that there seems to be no appreciable improvement in DL. The 1:8.5 ratio was therefore chosen for further studies due to its high DL and EE, size distribution and surface charge comparable to other formulations, and relatively small particle size (even though the size was greater than the 1:6 formulation$133 \mathrm{~nm}$ vs $112 \mathrm{~nm}$, respectively, it was still within the desired 50-200 nm range).

\section{Effect of Surfactant Concentration}

Andrographolide formulations with ethyl acetate organic solvent, 50:50 PLGA polymer (molecular weight 31.3-57.6 kDa), 1:8.5 drug-polymer ratio, and different PVA surfactant concentrations had a mean particle size in the range of $114-163 \mathrm{~nm}$, PI of $0.16-$ 0.20 , zeta potential of -10.1 to $-14.1 \mathrm{mV}$, DL of $1.2-2.8 \% \mathrm{w} / \mathrm{w}$, and $\mathrm{EE}$ of $12.6-27.3 \%$ as shown in Table 6.

The $1 \%(\mathrm{E} 1)$ and $2 \% \mathrm{w} / \mathrm{v}(\mathrm{E} 2)$ PVA formulations had the largest and smallest mean particle size, respectively, and there was no relationship between the size and surfactant concentration. The PVA concentration did not affect the size distribution and surface charge of the particles as similar PI and zeta potential were obtained in all the formulations. An increase in the surfactant concentration resulted in an increase in the amount of drug encapsulated up to the $2 \%$ concentration; a further increase caused a reduction in DL and EE as observed for the 2.5\% (E3), 3\% (E4), and 4\% w/v (E5) PVA concentrations. This can be attributed to the ability of the surfactant to improve the solubility of poorly water-soluble substances in aqueous medium (Vinarov et al., 2018); an increase in surfactant concentration will lead to more andrographolide present in the aqueous phase of the emulsion being lost during washing, resulting in lower DL and EE.

The $2 \% \mathrm{w} / \mathrm{v}$ PVA formulation was found to be the most suitable because it had the smallest particle size but with size distribution and surface charge comparable to other formulations and highest drug content and EE.

\section{In vitro Release Studies of Andrographolide Nanoformulation}

The release profiles of andrographolide from formulations having different lactide to glycolide ratios, organic solvent, and PLGA molecular weights are represented in Figures 1A-C. 

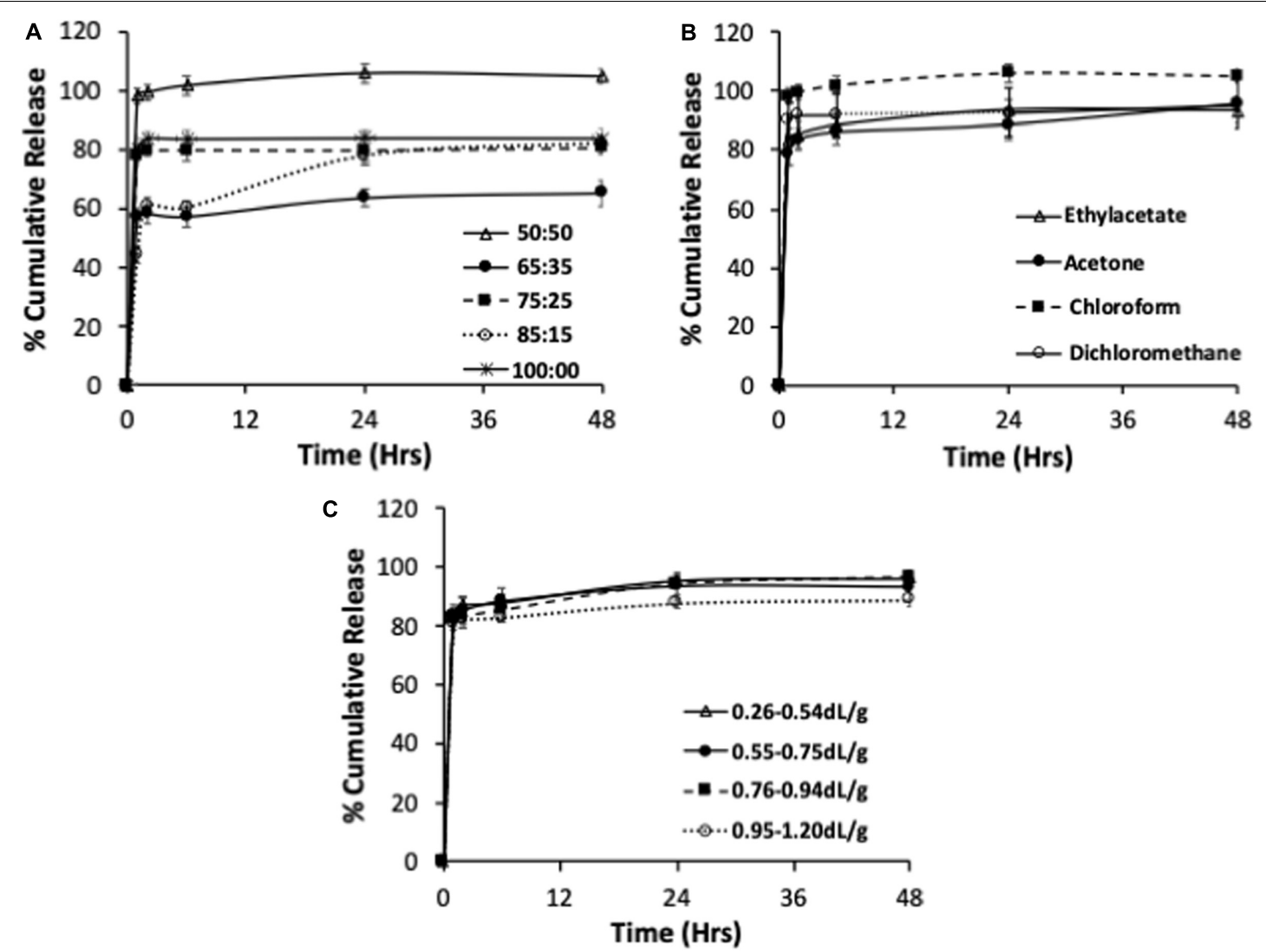

FIGURE 1 | In vitro release of andrographolide nanoformulations prepared using different lactide to glycolide ratios (A), organic solvent (B), and PLGA molecular weights (C). Data expressed as mean \pm S.D $(n=3)$.

TABLE 7 | Physicochemical properties and drug loading of optimized andrographolide nanoformulation.

\begin{tabular}{|c|c|c|c|c|c|}
\hline Formulation code & Particle size (nm) & Polydispersity index-PI & Zeta potential $(\mathrm{mV})$ & Drug loading (\%) & Encapsulation efficiency (\%) \\
\hline Ethyl acetate & $135 \pm 4^{\star \star \star}$ & $0.22 \pm 0.00^{\star \star \star}$ & $-11.7 \pm 2.4$ & $2.6 \pm 0.6^{\star}$ & $19.1 \pm 4.1^{\star \star \star}$ \\
\hline Chloroform & $194 \pm 2$ & $0.10 \pm 0.01$ & $-17.2 \pm 5.6$ & $1.3 \pm 0.2$ & $9.7 \pm 1.7$ \\
\hline
\end{tabular}

Results are expressed as mean $\pm S D(n=3)$.

*signifies $p<0.05$, ***signifies $p<0.001$ significant differences with respect to $85: 15$ chloroform formulation.

Drug release from polymeric dispersions can occur through several mechanisms including via polymer degradation, desorption from the particle surface followed by diffusion from the bulk, or a combination of these mechanisms (Alhakamy and Md, 2019). PLGA is known to undergo bulk erosion and release of hydrophobic drugs from PLGA matrices occurs through a combination of drug diffusion (dominant during the early phases) and polymer degradation (more dominant during terminal phase) (Makadia and Siegel, 2011). The formulations prepared using polymers of varying lactide to glycolide ratios released their total andrographolide content in 2-48 h (Figure 1A). The 75:25, 85:15 PLGA and 100:0 PLA resulted in similar amount of andrographolide release, and this was lower than the 50:50 formulation. The slowest drug release was observed for the 65:35 PLGA formulation. The mechanism(s) underlying this observation is unclear. One possibility is that reduction in the total drug release in the
$65: 35,75: 25,85: 15$, and 100\% PLA when compared to the 50:50 formulation might be due to the increase in the hydrophobic content of the polymer conferred by higher lactide content. This might have led to increased affinity of the drug to the polymer, resulting in slower drug release (Park, 1995; Lee et al., 2002). However, both 75:25 PLGA and 100 PLA formulations released their total drug content within $2 \mathrm{~h}$. In contrast, the $65: 35$ and 85:15 formulations demonstrated a gradual release over 24 and $48 \mathrm{~h}$, with an initial burst release of 57 and $60 \%$, respectively, in $2 \mathrm{~h}$. Thus, the release profile did not directly correlate with the lactide content or the hydrophobicity of the polymer. Differences in particle size and DL for the different formulations could have also contributed to the differences in the observed drug release profiles.

All the formulations prepared using different organic solvents released their andrographolide content between 24 and $48 \mathrm{~h}$ (Figure 1B). The chloroform and ethyl acetate nanoformulations 


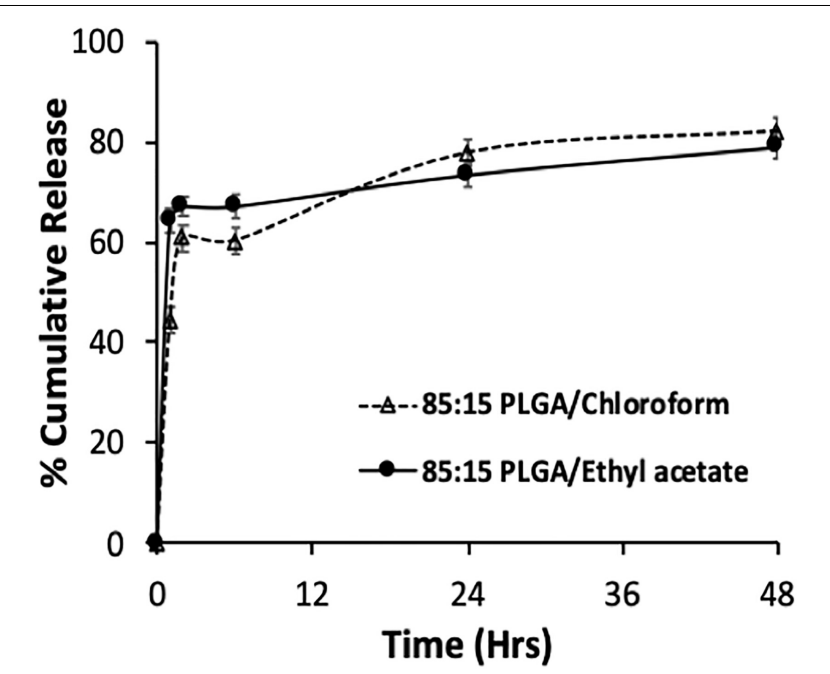

FIGURE 2 | In vitro release of andrographolide nanodispersion prepared using 85:15 PLGA polymer and chloroform or ethyl acetate as the organic solvent. Data expressed as mean $\pm \mathrm{SD}(n=3)$.

released their drug content in $24 \mathrm{~h}$ while the dichloromethane and acetone formulations release their drug over $48 \mathrm{~h}$. All the formulations resulted in a rapid initial burst release of at least $84 \%$ within $2 \mathrm{~h}$. The initial rapid release was slightly lower in ethyl acetate and acetone formulations than for dichloromethane and chloroform formulations. The 50:50 PLGA polymer appeared to result in rapid release of the drug content irrespective of the solvent used in the fabrication of the formulation.

The andrographolide nanoformulations obtained from 50:50 PLGA polymer of different molecular weights released their drug content in $24 \mathrm{~h}(6.7-31.3,31.3-57.6$, and $91.6-111.5 \mathrm{kDa}$ polymeric formulation) to $48 \mathrm{~h}(57.6-91.6 \mathrm{kDa}$ polymeric formulation) (Figure 1C). The andrographolide formulation prepared with a high molecular weight polymer, $91.6-111.5 \mathrm{kDa}$, demonstrated a slight reduction in the total andrographolide release $(88 \%)$ when compared with the $6.7-31.3,31.3-57.6$, and $57.6-91,6 \mathrm{kDa}$ formulations that resulted in similar drug release (96, 93, and 97\% andrographolide release, respectively). All the 50:50 PLGA inherent viscosity formulations showed a rapid initial release of at least $82 \%$ of its drug content within $2 \mathrm{~h}$.

The burst release observed in the formulations can be attributed to both the presence of surface-associated drug and the large surface area of PLGA nanoparticles, which allows for rapid drug diffusion. These physicochemical properties are influenced by factors such as molecular weight of the polymer, polymer concentration and hydrophilicity of the polymer (MohammadiSamani and Taghipour, 2015). Therefore, further optimization of the polymer properties may result in a formulation with less burst effect.

Considering that most of the drug was released in few hours in most formulations, the 85:15 PLGA polymer was chosen for the preparation of nanoparticle and subsequent evaluation of its antiproliferative activity on breast cancer cells because it exhibited sustained release potential and high total drug content release $(\sim 80 \%$ release over $48 \mathrm{~h})$. The andrographolide

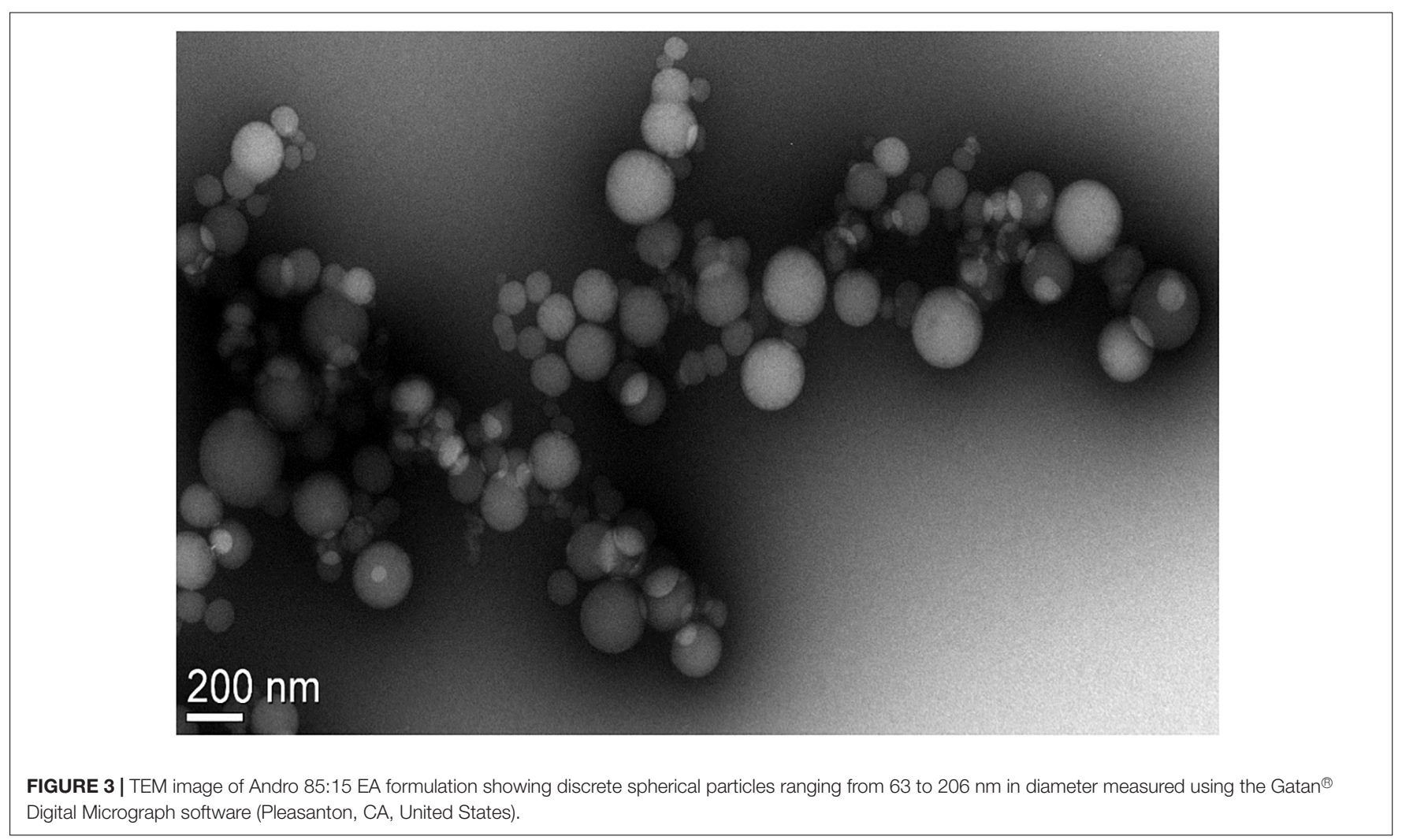




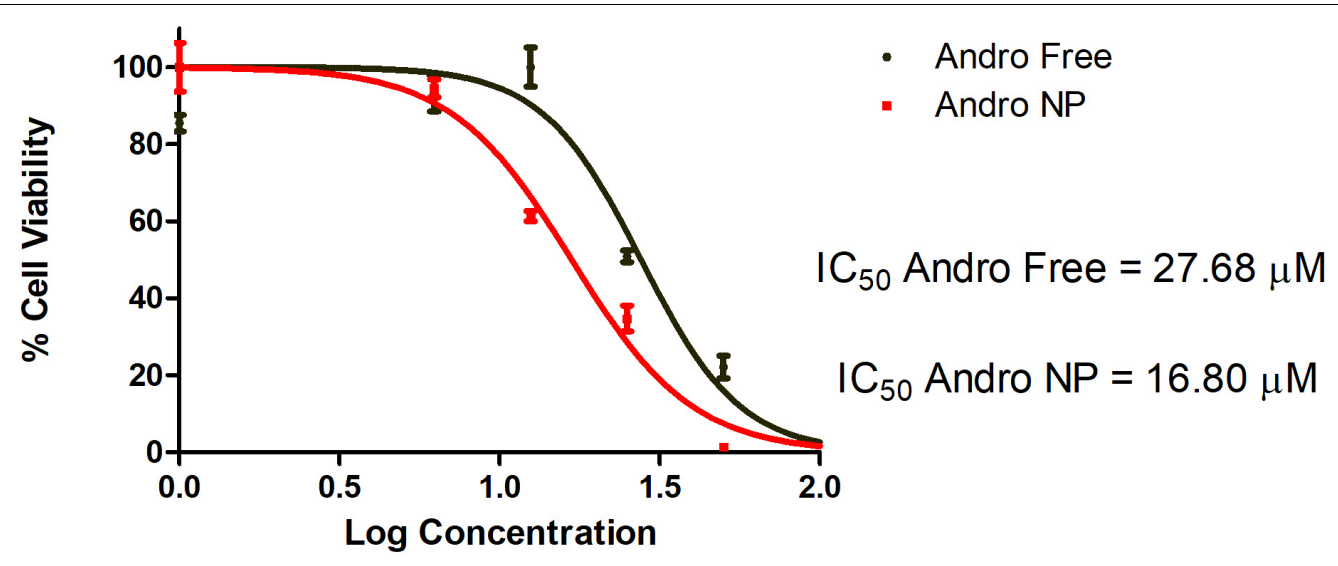

FIGURE 4 | Dose-response curve of andrographolide free drug and nanoformulation on LM2 cells following $48 \mathrm{~h}$ treatment. Andro Free, andrographolide free drug, Andro NP, andrographolide nanoformulation.

nanoformulation was made with ethyl acetate as the organic solvent (since it resulted in formulations with reduced particle size and increased DL), 85:15 PLGA polymer, drug-polymer ratio of 1:8.5 and 2\% PVA; physicochemical properties, DL, EE, and release of this formulation are shown in Table 7 and Figure 2.

The 85:15 ethyl acetate andrographolide formulation had smaller particle size, increased DL, higher EE, comparable zeta potential, and a more heterogenous particle size distribution when compared with the chloroform formulation. The formulations fabricated using ethyl acetate and chloroform released a total of 79 and $82 \%$, respectively, within $48 \mathrm{~h}$. Both formulations exhibited a similar release pattern, however, more andrographolide was released from the ethyl acetate formulation initially ( 64 vs $44 \%$ at 1 h; 67 vs $60 \%$ at $2-6$ h for ethyl acetate and chloroform, respectively). This can be attributed to the size of the formulation-the smaller the size, the larger the surface area and the faster the rate of drug release (Rizvi and Saleh, 2018). Based on these desirable properties of smaller size, increased $\mathrm{DL}$, and more sustained in vitro release profile, the formulation prepared using the 85:15 PLGA polymer and ethyl acetate as the organic solvent was chosen as the optimized formulation for cell culture studies.

\section{Surface Morphology of Optimized Andrographolide Formulation}

A TEM image of the 85:15 PLGA ethyl acetate formulation showed discrete, spherical particles with sizes ranging from 63 to $206 \mathrm{~nm}$ (Figure 3). This appeared to correlate well with the particle size and size distribution determined using DLS (Table 7).

\section{In vitro Anticancer Efficacy Studies With the Optimized Andrographolide Formulation \\ In vitro Acute Viability}

Initial studies evaluated the acute effect of the andrographolide free drug and the nanoformulation on cell viability over $48 \mathrm{~h}$.
This study showed that the nanoformulation was better than the free drug $\left(\mathrm{IC}_{50}\right.$ of $27.68 \mu \mathrm{M}$ for free drug vs $16.80 \mu \mathrm{M}$ for nanoformulation) as shown in Figure 4.

To determine the effect of blank particles and solvent (DMSO), the LM2 cells were treated with the same concentration of DMSO and blank PLGA nanoparticles present in the free drug and nanoformulation treated group. After $48 \mathrm{~h}$, the DMSO and blank PLGA nanoparticle treated cells showed similar viability (99.5\% and $100.8 \%$, respectively) as the untreated (100\%) group (Figure 5). This demonstrates that the DMSO solvent or the PLGA polymer did not have cytotoxic effects on the LM2 cells at the concentration utilized. As in the previous study, nanoformulation was more cytotoxic than the equivalent concentration of the free drug. Untreated cells were used as controls in further experiments since DMSO and blank PLGA nanoformulation demonstrated no cytotoxic activity.

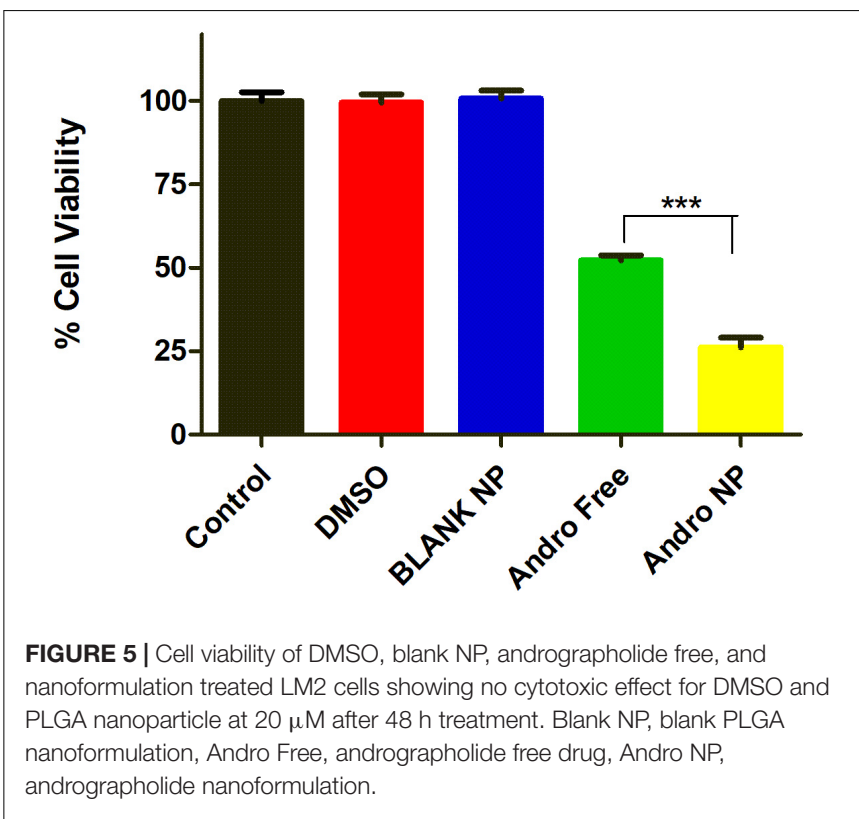




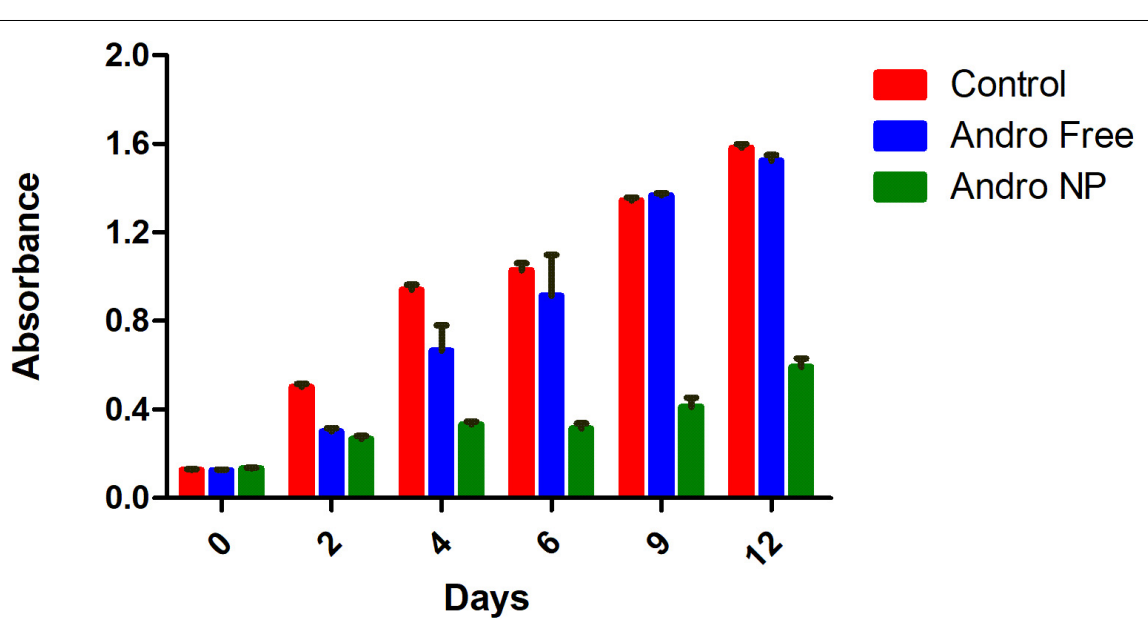

FIGURE 6 | Cell viability of untreated LM2 cells, andrographolide free and nanoformulation post treatment removal showing prolonged cytotoxic effect of andrographolide nanoformulation. Andro Free, andrographolide free drug, Andro NP, andrographolide nanoformulation.

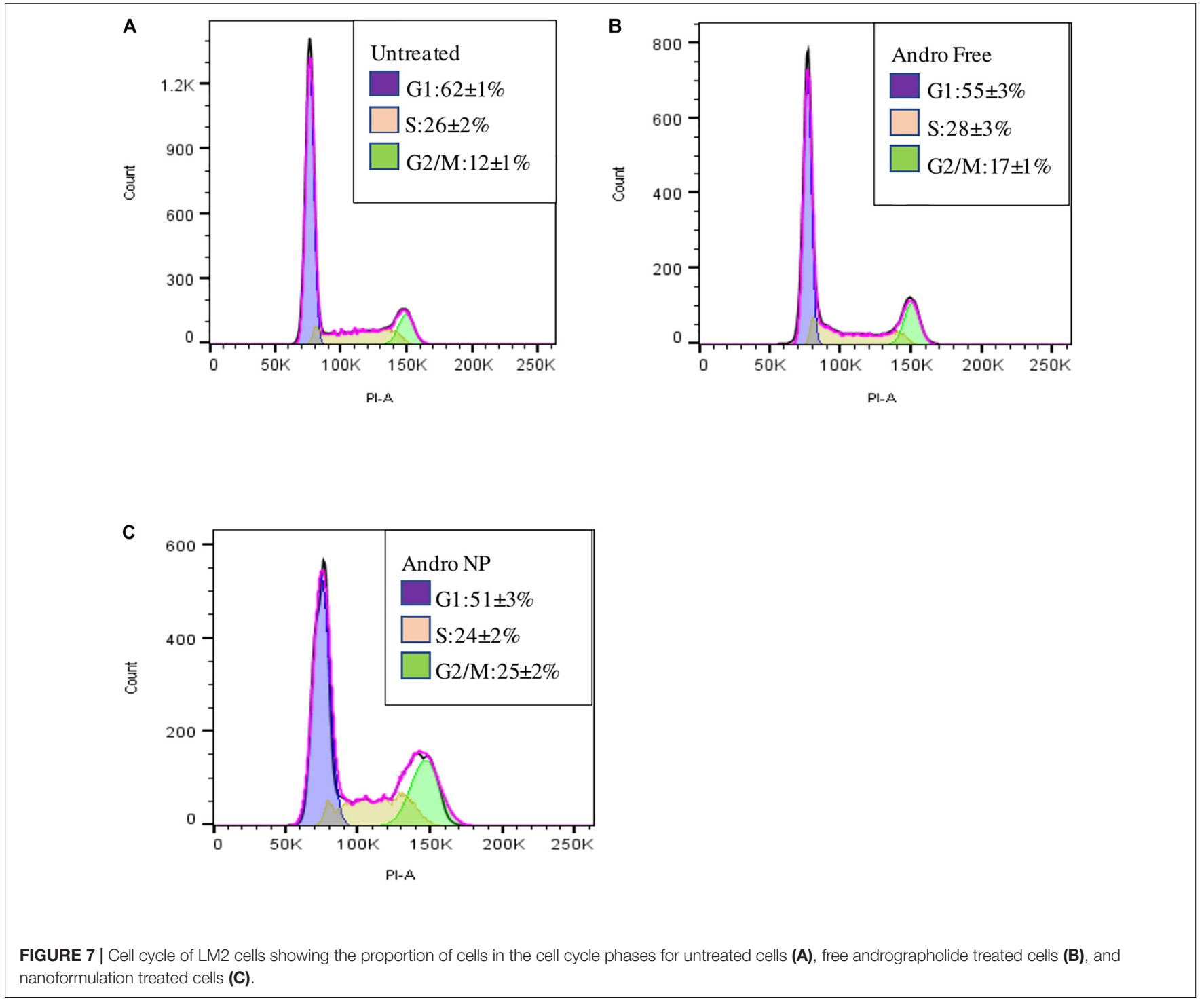




\section{In vitro Sustained Efficacy}

We then evaluated the effect of nanoformulation on cell viability over 12 days. The cell viability of andrographolide free drug, andrographolide nanoformulation and untreated cells (control) at various time points following treatment removal is shown in Figure 6.

Prior to treatment (day 0), the cells seeded showed similar absorbance, indicating similar number of cells present in the different groups. Upon treatment removal, the free drug treatment group showed a transient cytotoxic effect for up to 6 days post treatment. This effect was lost after 6 days, as demonstrated by the presence of similar number of viable cells as in the untreated group. In contrast, the cells treated with andrographolide nanoformulation maintained lower cell numbers upon treatment removal until the 12th day of the study. Thus, the nanoformulation demonstrated a sustained cytotoxic effect. This is in line with the findings of Panyam and Labhasetwar (2004). The sustained inhibition of cell proliferation observed in PLGA nanoformulation in that study was attributed to the sustained intracellular drug levels as opposed to that with the free drug in which intracellular drug levels decreased drastically upon removal of the treatment (Panyam et al., 2002; Panyam and Labhasetwar, 2004).

\section{Cell Cycle Analysis}

Cell cycle analysis demonstrated accumulation of cells in the $\mathrm{G} 2 / \mathrm{M}$ phase in both andrographolide free drug and nanoformulation compared to that with untreated cells as shown in Figures 7A-C.

The andrographolide free drug and nanoformulation treatments resulted in a decrease in the number of cells in the G1 phase with an increase in the G2/M phase when compared to that with the untreated cells. This is in line with a study carried out by Banerjee et al., in which andrographolide elicited cell cycle arrest in the G2/M phase in MDA-MB-231 cells-the parent cell line of LM2 cells used in this study (Banerjee et al., 2016). A higher number of cells were in the G2/M phase for the nanoformulation treated group than in the group treated with the free drug, demonstrating improved therapeutic effect with the nanoformulation.

\section{CONCLUSION}

A polymeric nanoformulation of andrographolide was developed, and the effect of different formulation parameters on physicochemical properties and release profile was determined to

\section{REFERENCES}

Ajaya Kumar, R., Sridevi, K., Vijaya Kumar, N., Nanduri, S., and Rajagopal, S. (2004). Anticancer and immunostimulatory compounds from Andrographis paniculata. J. Ethnopharmacol. 92, 291-295. doi: 10.1016/j.jep.2004. 03.004

Alhakamy, N. A., and Md, S. (2019). Repurposing Itraconazole Loaded PLGA Nanoparticles for Improved Antitumor Efficacy in Non-Small Cell Lung Cancers. Pharmaceutics 11, 685-700. doi: 10.3390/pharmaceutics 11120685 obtain a formulation with desirable properties. Encapsulation of andrographolide in nanoparticles of approximately 100-150 nm size was achieved using ethyl acetate as the organic solvent. Nanoparticles formulated using 85:15 lactide to glycolide ratio PLGA polymer, drug-polymer ratio of 1:8.5, 2\% PVA, and ethyl acetate as the organic solvent were identified as the optimized formulation for andrographolide. This formulation demonstrated enhanced and sustained inhibition of proliferation of triple negative LM2 breast cancer cells when compared to the free drug. This formulation can serve as a template for further development of andrographolide as a potential anticancer agent for clinical use.

\section{DATA AVAILABILITY STATEMENT}

The raw data supporting the conclusions of this article will be made available by the authors, without undue reservation.

\section{AUTHOR CONTRIBUTIONS}

BO, CA, OO, and JP conceptualized the study. BO and JP developed the methods for the study. BO carried out the experiments, analyzed the data obtained, and wrote the manuscript draft in collaboration with JP. CA, OO, CI, and JP supervised the research and reviewed the manuscript. JP acquired the funds for the study. All authors have read and agreed to the published version of the manuscript.

\section{FUNDING}

This research was funded by internal funds from the University of Minnesota.

\section{ACKNOWLEDGMENTS}

We thank the United States Department of State for the award of the Fulbright Foreign Student Program fellowship to BO. We also thank Drishti Sehgal and Vidhi Khanna, Department of Pharmaceutics, Panyam Laboratory, University of Minnesota for the cell culture, and flow cytometry training and assistance. The TEM imaging was performed with the assistance of Han Seung Lee and Wei Zhang in the Characterization Facility (University of Minnesota), which receives partial support from NSF through the MRSEC program.

Bahrami, B., Hojjat-Farsangi, M., Mohammadi, H., Anvari, E., Ghalamfarsa, G., Yousefi, M., et al. (2017). Nanoparticles and targeted drug delivery in cancer therapy. Immunol. Lett. 190, 64-83. doi: 10.1016/j.imlet.2017. 07.015

Banerjee, M., Chattopadhyay, S., Choudhuri, T., Bera, R., Kumar, S., Chakraborty, B., et al. (2016). Cytotoxicity and cell cycle arrest induced by andrographolide lead to programmed cell death of MDA-MB-231 breast cancer cell line. J. Biomed. Sci. 23, 40-55. doi: 10.1186/s12929-0160257-0 
Betala, S., Mohan Varma, M., and Abbulu, K. (2018). Formulation and evaluation of polymeric nanoparticles of an antihypetensive drug for gastroretention. J. Drug Deliv. Ther. 8, 82-86. doi: 10.22270/jddt.v8i6.2018

Bharathala, S., and Sharma, P. (2019). "“Biomedical applications of nanoparticles,,", in Nanotechnology in Modern Animal Biotechnology: Concepts and Applications, eds S. Maurya and P. K. Singh (Amsterdam: Elsevier), 113-132.

Bhatia, S. (2016). Nanoparticles Types, Classification, Characterization, Fabrication Methods and Drug Delivery Applications in Natural Polymer Drug Delivery Systems: Nanoparticles, Plants, and Algae. Switzerland: Springer International, 33-93.

Bray, F., Ferlay, J., Soerjomataram, I., Siegel, R. L., Torre, L. A., and Jemal, A. (2018). Global cancer statistics 2018: GLOBOCAN estimates of incidence and mortality worldwide for 36 cancers in 185 countries. CA. Cancer J. Clin. 68, 394-424. doi: 10.3322/caac. 21492

Clarke, S. P. (2013). Development of Hierarchical Magnetic Nanocomposite Materials for Biomedical Applications. Dissertation/Ph.D, Dublin: Dublin City University.

Danaei, M., Dehghankhold, M., Ataei, S., Hasanzadeh Davarani, F., Javanmard, R., Dokhani, A., et al. (2018). Impact of particle size and polydispersity index on the clinical applications of lipidic nanocarrier systems. Pharmaceutics 10, 1-17. doi: 10.3390/pharmaceutics10020057

Danhier, F., Ansorena, E., Silva, J. M., Coco, R., Le Breton, A., and Préat, V. (2012). PLGA-based nanoparticles: An overview of biomedical applications. J. Control. Release 161, 505-522. doi: 10.1016/J.JCONREL.2012.01.043

Ferlay, J., Colombet, M., Soerjomataram, I., Mathers, C., Parkin, D. M., Piñeros, M., et al. (2019). Estimating the global cancer incidence and mortality in 2018: GLOBOCAN sources and methods. Int. J. Cancer 144, 1941-1953. doi: 10.1002/ ijc. 31937

Ferlay, J., Soerjomataram, I., Dikshit, R., Eser, S., Mathers, C., Rebelo, M., et al. (2015). Cancer incidence and mortality worldwide: sources, methods and major patterns in GLOBOCAN 2012. Int. J. cancer 136, E359-E386. doi: 10.1002/ijc. 29210

Gentile, P., Chiono, V., Carmagnola, I., and Hatton, P. V. (2014). An Overview of Poly(lactic-co-glycolic) Acid (PLGA)-Based Biomaterials for Bone Tissue Engineering. Int. J. Mol. Sci. 15, 3640-3659. doi: 10.3390/IJMS15033640

Ghosh, P., Mondal, S., and Bera, T. (2016). Preparation and characterization of andrographolide nanoparticles for visceral leishmaniasis chemotherapy: In vitro and in vivo evaluations. Int. J. Pharm. Pharm. Sci. 8, 102-107. doi: 10.22159/ijpps.2016v8i12.14773

Grabowski, N., Hillaireau, H., Vergnaud, J., Tsapis, N., Pallardy, M., KerdineRömer, S., et al. (2015). Surface coating mediates the toxicity of polymeric nanoparticles towards human-like macrophages. Int. J. Pharm. 482, 75-83. doi: 10.1016/j.ijpharm.2014.11.042

Hadjzadeh, M. A., Tavakol, A. J., Ghorbani, A., and Shakeri, M. (2006). The effects of aqueous extract of Garlic (Allium sativum L.) on laryngeal cancer cells (Hep-2) and L929 cells in vitro. J. Med. Plants 2, 41-48.

Hickey, J. W., Santos, J. L., Williford, J. M., and Mao, H. Q. (2015). Control of polymeric nanoparticle size to improve therapeutic delivery. J. Control. Release 219, 536-547. doi: 10.1016/j.jconrel.2015.10.006

Honary, S., and Zahir, F. (2013). Effect of zeta potential on the properties of nanodrug delivery systems - A review (Part 2). Trop. J. Pharm. Res. 12, 265-273. doi: $10.4314 /$ tjpr.v12i2.20

Hosseini, A., and Ghorbani, A. (2015). Cancer therapy with phytochemicals: evidence from clinical studies. Avicenna J. phytomedicine 5, 84-97. doi: 10 . 22038/ajp.2015.3872

Igarashi, E. (2008). Factors affecting toxicity and efficacy of polymeric nanomedicines. Toxicol. Appl. Pharmacol. 229, 121-134. doi: 10.1016/j.taap. 2008.02.007

International Conference on Harmonization (2005). ICH Topic Q 2 (R1) Validation of Analytical Procedures: Text and Methodology Step 5 Note for Guidance on Validation of Analytical Procedures: Text and Methodology (CPMP/ICH/381/95) Approval by CPMP November 1994 Date for coming into operation. Available online at: http://www.emea.eu.int [Accessed October 30, 2020]

Jacob, S., Nair, A. B., and Shah, J. (2020). Emerging role of nanosuspensions in drug delivery systems. Biomater. Res. 24, 1-16. doi: 10.1186/s40824-020-0184-8

Jain, A. K., and Thareja, S. (2019). In vitro and in vivo characterization of pharmaceutical nanocarriers used for drug delivery. Artif. Cells Nanomed. Biotechnol. 47, 524-539. doi: 10.1080/21691401.2018.1561457
Jarukamjorn, K., and Nemoto, N. (2008). Pharmacological aspects of Andrographis paniculata on health and its major diterpenoid constituent andrographolide. J. Heal. Sci. 54, 370-381. doi: 10.1248/jhs.54.370

Jayakumar, T., Hsieh, C.-Y., Lee, J.-J., and Sheu, J.-R. (2013). Experimental and Clinical Pharmacology of Andrographis paniculata and Its Major Bioactive Phytoconstituent Andrographolide. Evid. Based. Complement. Alternat. Med. 2013, 846740-846755. doi: 10.1155/2013/846740

Kedar, U., Phutane, P., Shidhaye, S., and Kadam, V. (2010). Advances in polymeric micelles for drug delivery and tumor targeting. Nanomed. Nanotechnol. Biol. Med. 6, 714-729. doi: 10.1016/j.nano.2010.05.005

Kim, H., Niu, L., Larson, P., Kucaba, T. A., Murphy, K. A., James, B. R., et al. (2018a). Polymeric nanoparticles encapsulating novel TLR7/8 agonists as immunostimulatory adjuvants for enhanced cancer immunotherapy. Biomaterials 164, 38-53. doi: 10.1016/j.biomaterials.2018.02.034

Kim, H., Sehgal, D., Kucaba, T. A., Ferguson, D. M., Griffith, T. S., and Panyam, J. (2018b). Acidic pH-responsive polymer nanoparticles as a TLR7/8 agonist delivery platform for cancer immunotherapy. Nanoscale 10, 20851-20862. doi: 10.1039/c8nr07201a

Kumari, A., Yadav, S. K., and Yadav, S. C. (2010). Biodegradable polymeric nanoparticles based drug delivery systems. Colloids Surf. B. Biointerfaces 75, 1-18. doi: 10.1016/j.colsurfb.2009.09.001

Lè Ne Teiten, M.-H., Gaascht, F., Dicato, M., and Diederich, M. (2013). Anticancer bioactivity of compounds from medicinal plants used in European medieval traditions. Biochem. Pharmacol. 86, 1239-1247. doi: 10.1016/j.bcp.2013. 08.007

Lee, W., Park, J., Yang, E. H., Suh, H., Kim, S. H., Chung, D. S., et al. (2002). Investigation of the factors influencing the release rates of cyclosporin A-loaded micro- and nanoparticles prepared by high-pressure homogenizer. J. Control. Release 84, 115-123. doi: 10.1016/s0168-3659(02)00239-0

Levita, J., Nawawi, A., Mutalib, A., and Ibrahim, S. (2010). Andrographolide: A Review of its Anti-inflammatory Activity via Inhibition of NF-kappaB Activation from Computational Chemistry Aspects. Int. J. Pharmacol. 6, 569576. doi: 10.3923/ijp.2010.569.576

Lim, J. C. W., Chan, T. K., Ng, D. S., Sagineedu, S. R., Stanslas, J., and Wong, W. F. (2012). Andrographolide and its analogues: versatile bioactive molecules for combating inflammation and cancer. Clin. Exp. Pharmacol. Physiol. 39, 300-310. doi: 10.1111/j.1440-1681.2011.05633.x

Makadia, K., and Siegel, S. J. (2011). Poly Lactic-co-Glycolic Acid (PLGA) as biodegradable controlled drug delivery carrier. Polymers 3, 1377-1397. doi: 10.3390/polym3031377

Mishra, S. K. (2016). Andrographolide and analogues in cancer prevention. Front. Biosci. 7:292-304. doi: 10.2741/e732

Mohammadi-Samani, S., and Taghipour, B. (2015). PLGA micro and nanoparticles in delivery of peptides and proteins; problems and approaches. Pharm. Dev. Technol. 20, 385-393. doi: 10.3109/10837450.2014.882940

Monsuez, J. J., Charniot, J. C., Vignat, N., and Artigou, J. Y. (2010). Cardiac sideeffects of cancer chemotherapy. Int. J. Cardiol. 144, 3-15. doi: 10.1016/j.ijcard. 2010.03.003

Niranjan, A., Tewari, S. K., and Lehri, A. (2010). Biological activities of Kalmegh (Andrographis paniculata Nees) and its active principles-A review. Indian J. Nat. Prod. Resour. 1, 125-135.

Nussbaumer, S., Bonnabry, P., Veuthey, J.-L., and Fleury-Souverain, S. (2011). Analysis of anticancer drugs: A review. Talanta 85, 2265-2289. doi: 10.1016/ j.talanta.2011.08.034

Oseni, B. A., Azubuike, C. P., Okubanjo, O. O., and Igwilo, C. I. (2020). In Vitro Cytotoxic Effect of Andrographolide On MDA-MB-231-LM2 Breast Cancer Cells and Its Formulation and Characterization As An Emulsion. Trop J. Nat. Prod. Res. 4, 1-7. doi: 10.26538/tjnpr/v4i1.1

Pal, S. L., Jana, U., Manna, P. K., Mohanta, G. P., and Manavalan, R. (2011). Nanoparticle: An overview of preparation and characterization. J. Appl. Pharm. Sci. 1, 228-234.

Pandey, G., and Rao, C. H. (2018). Andrographolide: its pharmacology, natural bioavailability and current approaches to increase its content in Andrographis paniculata. Int. J. Complement Alt. Med. 11, 355-360. doi: 10.15406/ijcam.2018. 11.00425

Panyam, J., and Labhasetwar, V. (2004). Sustained Cytoplasmic Delivery of Drugs with Intracellular Receptors Using Biodegradable Nanoparticles. Mol. Pharm. 1, 77-84. doi: 10.1021/mp034002c 
Panyam, J., Zhou, W. Z., Prabha, S., Sahoo, S. K., and Labhasetwar, V. (2002). Rapid endo-lysosomal escape of poly(DL-lactide-co-glycolide) nanoparticles: Implications for drug and gene delivery. FASEB J. 16, 1217-1226. doi: 10.1096/ fj.02-0088com

Park, T. G. (1995). Degradation of poly(lactic-co-glycolic acid) microspheres: effect of copolymer composition. Biomaterials 16, 1123-1130. doi: 10.1016/01429612(95)93575-x

Pauli, G., Tang, W.-L., and Li, S.-D. (2019). Development and Characterization of the Solvent-Assisted Active Loading Technology (SALT) for Liposomal Loading of Poorly Water-Soluble Compounds. Pharmaceutics 11, 465-476. doi: 10.3390/ pharmaceutics11090465

Petros, R. A., and DeSimone, J. M. (2010). Strategies in the design of nanoparticles for therapeutic applications. Nat. Rev. Drug Discov. 9, 615-627. doi: 10.1038/ nrd2591

Rajagopal, S., Kumar, R. A., Deevi, D. S., Satyanarayana, C., and Rajagopalan, R. (2003). Andrographolide, a potential cancer therapeutic agent isolated from Andrographis paniculata. J. Exp. Ther. Oncol. 3, 147-158. doi: 10.1046/j.13594117.2003.01090.x

Rizvi, S. A. A., and Saleh, A. M. (2018). Applications of nanoparticle systems in drug delivery technology. Saudi Pharm. J. 26, 64-70. doi: 10.1016/j.jsps.2017. 10.012

Roy, P., Das, S., Mondal, A., Chatterji, U., and Mukherjee, A. (2012). Nanoparticle Engineering Enhances Anticancer Efficacy of Andrographolide in MCF-7 Cells and Mice Bearing EAC. Curr. Pharm. Biotechnol. 13, 2669-2681. doi: 10.2174/ 138920112804724855

Sadat, S. M. A., Jahan, S. T., and Haddadi, A. (2016). Effects of Size and Surface Charge of Polymeric Nanoparticles on in Vitro and in Vivo Applications. J. Biomater. Nanobiotechnol. 07, 91-108. doi: 10.4236/jbnb.2016.72011

Sawant, K., and Dodiya, S. (2008). Recent Advances and Patents on Solid Lipid Nanoparticles. Recent Pat. Drug Deliv. Formul. 2, 120-135. doi: 10.2174/ 187221108784534081

Sheeja, K., and Kuttan, G. (2007). Activation of Cytotoxic T Lymphocyte Responses and Attenuation of Tumor Growth in vivo by Andrographis paniculata Extract and Andrographolide. Immunopharmacol. Immunotoxicol. 29, 81-93. doi: 10. 1080/08923970701282726

Shu, L., Cheung, K. L., Khor, T. O., Chen, C., and Kong, A. N. (2010). Phytochemicals: cancer chemoprevention and suppression of tumor onset and metastasis. Cancer Metastasis. Rev. 29, 483-502. doi: 10.1007/s10555-0109239-y

Takimoto, C. H., and Calvo, E. (2005). "Principles of oncologic pharmacotherapy," in Cancer Management: A Multidisciplinary Approach, eds R. Pazdur,
L. D. Wagman, and K. Camphausen (London: Cmp United Business Media), 19.

Tan, W., Lu, J., Huang, M., Li, Y., Chen, M., Wu, G., et al. (2011). Anti-cancer natural products isolated from chinese medicinal herbs. Chin. Med. 6, 27-41. doi: 10.1186/1749-8546-6-27

Toti, U. S., Guru, B. R., Hali, M., Mcpharlin, C., Wykes, S. M., Panyam, J., et al. (2011). Targeted Delivery of Antibiotics to Intracellular Chlamydial Infections using PLGA Nanoparticles. Biomaterials 32, 6606-6613. doi: 10. 1016/j.biomaterials.2011.05.038

Vinarov, Z., Katev, V., Radeva, D., Tcholakova, S., and Denkov, N. D. (2018). Micellar solubilization of poorly water-soluble drugs: effect of surfactant and solubilizate molecular structure. Drug Dev. Ind. Pharm. 44, 677-686. doi: 10. 1080/03639045.2017.1408642

Vineeth, P., Rao Vadaparthi, P. R., Kumar, K., Babu, B. D. J., Veerabhadra Rao, A., and Suresh Babu, K. (2014). Influence of organic solvents on nanoparticle formation and surfactants on release behaviour in-vitro using costunolide as model anticancer agent. Int. J. Pharm. Pharm. Sci. 6, 638-645.

Wilken, R., Veena, M. S., Wang, M. B., and Srivatsan, E. S. (2011). Curcumin: A review of anti-cancer properties and therapeutic activity in head and neck squamous cell carcinoma. Mole. Cancer 10, 1-19. doi: 10.1186/1476-459810-12

Yallapu, M. M., Gupta, B. K., Jaggi, M., and Chauhan, S. C. (2010). Fabrication of curcumin encapsulated PLGA nanoparticles for improved therapeutic effects in metastatic cancer cells. J. Colloid Interface Sci. 351, 19-29. doi: 10.1016/j.jcis. 2010.05.022

Yin Win, K., and Feng, S. S. (2005). Effects of particle size and surface coating on cellular uptake of polymeric nanoparticles for oral delivery of anticancer drugs. Biomaterials 26, 2713-2722. doi: 10.1016/j.biomaterials.2004. 07.050

Conflict of Interest: The authors declare that the research was conducted in the absence of any commercial or financial relationships that could be construed as a potential conflict of interest.

Copyright (C) 2021 Oseni, Azubuike, Okubanjo, Igwilo and Panyam. This is an openaccess article distributed under the terms of the Creative Commons Attribution License (CC BY). The use, distribution or reproduction in other forums is permitted, provided the original author(s) and the copyright owner(s) are credited and that the original publication in this journal is cited, in accordance with accepted academic practice. No use, distribution or reproduction is permitted which does not comply with these terms. 